\title{
Experimental study of surface roughness in Electric Discharge Machining (EDM) based on Grey Relational Analysis
}

\author{
Ashanira Mat Deris ${ }^{1, *}$, Azlan Mohd Zain ${ }^{1}$, Roselina Sallehuddin ${ }^{1}$, and Safian Sharif ${ }^{2}$ \\ ${ }^{1}$ Soft Computing Research Group, Faculty of Computing, UTM, Johor, Malaysia \\ ${ }^{2}$ Faculty of Mechanical Engineering, UTM, Johor, Malaysia
}

\begin{abstract}
Electric Discharge Machining (EDM) is one of the modern machining which is capable in handling hard and difficult-to-machine material. The successful of EDM basically depends on its performances such as surface roughness (Ra), material removal rate (MRR), electrode wear rate (EWR) and dimensional accuracy (DA). Ra is considered as the most important performance due to it role as a technological quality measurement for a product and also a factor that significantly affects the manufacturing process. This paper presents the experimental study of surface roughness in die sinking EDM using stainless steel SS316L with copper impregnated graphite electrode. The machining experimental is conducted based on the two levels full factorial design of design of experiment (DOE) with five machining parameters which are peak current, servo voltage, servo speed, pulse on time and pulse off time. The results were analyzed using grey relational analysis (GRA) and it was found that pulse on time and servo voltage give the most influence to the Ra value.
\end{abstract}

\section{Introduction}

Electric disharge machining (EDM) which is firstly introduced in manufacturing industries in late 1940s, is one of the earlier non-conventional machining processes. EDM is well known as one of the most widely used and successfully applied machining processes for the geometrically complex parts, hard materials and difficult-to-machine materials [1]. The successful of EDM depends on its performances such as surface roughness (Ra). Surface roughness is considered as one of the most important performances in machining process that refers to the product quality [2,3]. According to Keskin et al. [4], surface roughness is the most measured performance in EDM compared with other performances such as tool wear and material removal rate [5]. In most cases, in the industries, surface roughness is a technical requirement needed for mechanical products. Practically, for the machine parts, surface roughness plays an important role in fatigue strength, wear resistance, tensile, and ductility [6]. For achieving optimal solution of surface roughness, a proper selection of machining parameters is essential. Surface roughness value generally influenced by many factors such as machining parameters, work piece properties, cutting phenomena and type

\footnotetext{
*Corresponding author : ashanira.md@gmail.com
} 
of cutting tools [7]. Several machining parameters that have been widely studied by researchers are pulse on time, pulse off time, duty factor, servo voltage and peak current. The value of surface roughness is controlled by sparks frequency during the machining process, which is the number of discharges per second. The higher energy applied leads to the higher amount of material removed which can be also causing a rougher surface finish.

Ramirez and Franco [8] reports the experimental study of Ra in EDM process using AISI 316 stainless steel with copper electrodes. Two machining parameters were considered which are depth of penetration and current intensity. The experiment results proved that both considered parameters gave the high influence on surface roughness value. Bose and Mahapatra [9] investigated surface roughness in die sinking EDM process on AISI H31 tool steel. Discharge gap current, spark gap pulse on time and pulse off time were evaluated and analyzed in order to find which parameters give the most influence to the surface roughness. The experiment design based on Taguchi method L27 orthogonal array. The result showed that pulse on time gives the most influence to $\mathrm{Ra}$ value which contributes $47.24 \%$. Surface roughness decreased when pulse on time value increased.

Mir et al. [10] applied Response Surface Methodology (RSM) to analyze machining parameters of surface roughness in powder mixed EDM. The experiment is conducted based on central composite design (CCM) while RSM is used to develop, improve and optimized the experiments. Discharge current, pulse on time and concentration of Aluminum powder added into dielectric fluid were chosen as machining parameters with H11 steel as a work piece. The results showed that powder concentration and peak current are the most significant parameters to the surface roughness. Tang and Du [11] investigated surface roughness value in green EDM process which tap water is used as dielectric fluid. The experiment is conducted using Taguchi L9 orthogonal array with four machining parameters which are pulse on time, discharge current, gap voltage and lifting height. The work piece used is Ti-6Al-4V alloy. The results found that the optimal values of machining parameters are $11 \mathrm{~A}$ discharge current, $30 \mathrm{~V}$ gap voltage, $3 \mathrm{~mm}$ lifting height, $30 \%$ duty factor and $30 \mu$ s pulse duration. Surface roughness decreased from $2.37 \mu \mathrm{m}$ to $1.93 \mu \mathrm{m}$ with the improvement of $18.9 \%$ when tap water is used as a dielectric fluid.

Wired EDM is also one of the EDM types. Ekici et al. [12] evaluates the surface roughness in wire electric discharge machining (WEDM) of high density $\mathrm{Al} / \mathrm{B}_{4} \mathrm{C}$ metal matrix composites using Taguchi method. Five machining parameters which are pulse on time, wire speed, pulse off time, reinforcement percentage and wire tension were considered as the control factors. The experiment design was conducted based on Taguchi L18 orthogonal array. The results showed that pulse on time is the most significant factors that affects the surface roughness value. Ikram et al. [13] investigated WEDM machining parameters which are wire feed velocity, wire tension, pulse on time, dielectric pressure, pulse off time, open voltage and servo voltage, to the surface roughness value using Taguchi approach. The experiment was conducted based on Taguchi L18 orthogonal array and the experiment results were analyzed based on analysis of variance (ANOVA) and signal-to-noise $(\mathrm{S} / \mathrm{N})$ ratio analysis. The results showed that pulse on time gives the most effects to the surface roughness value.

The main objective of this study is to perform the machining experiment of EDM and to investigate the machining parameters that give the most effect to the surface roughness. The experiment was conducted on stainless steel 316L work piece with copper impregnated graphite electrode in die sinking EDM. The experiment result has been collected and analyzed using GRA in order to investigate the significant parameters to the surface roughness value. 


\section{Design of Experiments and Experiment Procedure}

The proper selection of EDM machining parameters and experimental design are important in order to get successful machining process with desired output performance. In this study, five parameters were considered. They are peak current, pulse on time, servo voltage, pulse off time and servo speed. The design setting of the machining parameters which acts as input parameters need to be determined prior to the machining process. In this study, the experiment is conducted based on two levels full factorial design. The selection of the range value for each input factors are based on manual EDM handbook and also based on the previous researchers. Table 1 shows the range value of EDM input parameters.

Table 1. The range value of EDM parameters

\begin{tabular}{|l|c|c|c|}
\hline \multirow{2}{*}{ Variables } & \multirow{2}{*}{ Unit } & \multicolumn{2}{|c|}{ Levels } \\
\cline { 3 - 4 } & & $\mathbf{1}$ & $\mathbf{2}$ \\
\hline Peak Current (IP) & {$[\mathrm{A}]$} & 5.7 & 10.5 \\
\hline Pulse on time (ON) & {$[\mu \mathrm{s}]$} & 100 & 200 \\
\hline Pulse of time (OFF) & {$[\mu \mathrm{s}]$} & 50 & 70 \\
\hline Servo Voltage (SV) & {$[\mathrm{V}]$} & 30 & 90 \\
\hline Servo Speed (S) & - & 74 & 92 \\
\hline
\end{tabular}

The experiment design consists of two level full factorial design. The input parameters; peak current, pulse on time, pulse off time, servo voltage and servo speed are classified into two levels, high and low which labels as ' 1 ' and ' 2 '. The design indicates 32 number of experiments. The machining experiment is conducted using AG40L die sinking EDM process as shown in Fig. 1. The material used in this experiment is stainless steel SS316L and the electrode is copper impregnated graphite. The general setting of EDM setup is shown in Table 2.

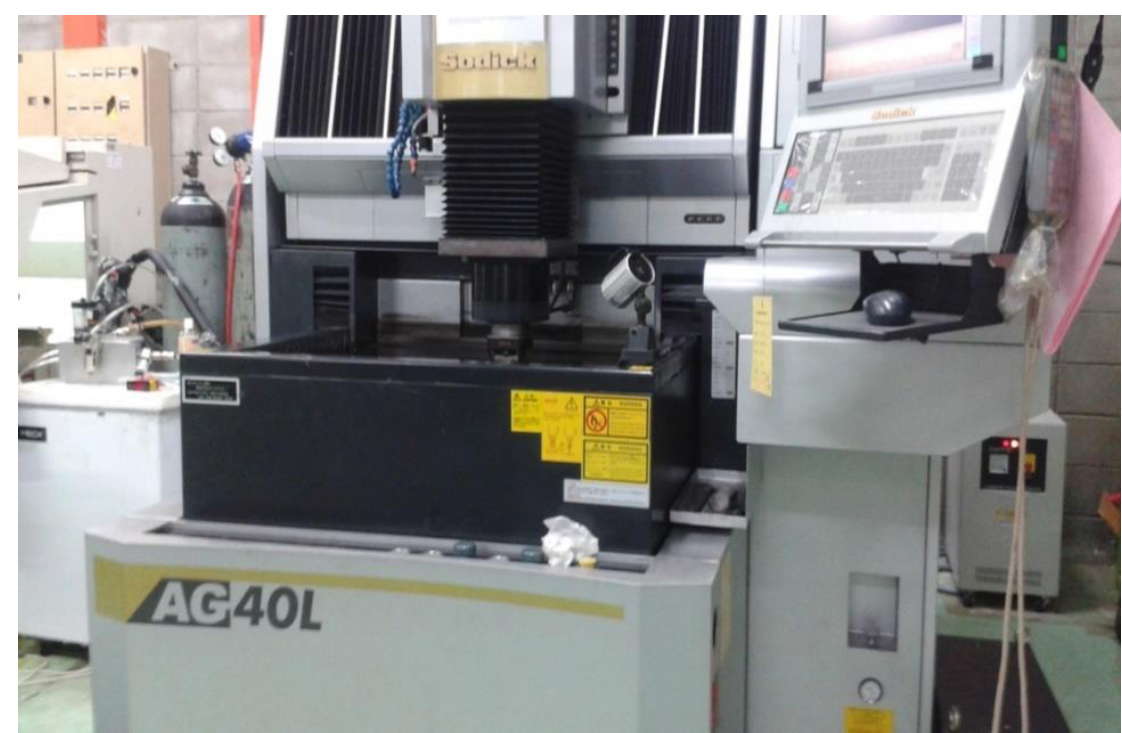

Fig. 1. AG40L model of die sinking EDM. 
Table 2. General EDM setup.

\begin{tabular}{|l|l|}
\hline Variables & Setup \\
\hline Work piece & Stainless Steel 316L (100mm x 50mm x 10mm) \\
\hline Electrode & Copper impregnated graphite (8mm) \\
\hline Depth of hole & $2 \mathrm{~mm}$ \\
\hline Polarity & Positive \\
\hline Flushing & On \\
\hline Dielectric Fluid & Oil \\
\hline
\end{tabular}

\section{Results and Analysis}

This section discusses the experimental result and analysis of surface roughness value using Grey Relational Grade (GRA). Surface roughness values were measured using surface roughness tester and the result is analyzed based on GRA method. GRA which is firstly introduced by Professor Deng Julong in Grey sytem is one of the analysis technique [14]. The first step in GRA is data preprocessing. Normalization of the data is calculated based on the characteristic of the input parameters which is also known as sequence data. This study applies "lower the better" which is used to compare levels in GRA, the formula is given in Eq.1:

$$
x^{*}{ }_{i}(k)=\frac{\max _{i}^{o}(k)-x^{*}{ }_{i}(k)}{\max x_{i}^{o}(k)-\min x_{i}^{0}(k)}
$$

Relationship between the ideal and normalized experimental results is express using grey relational coefficient (GRC) which is calculated using Eq.2:

$$
\xi_{i}(k)=\frac{\Delta \min +\xi \cdot \Delta \max }{\Delta_{0 i}(k)+\xi \cdot \Delta \max }
$$

Where $\xi$ is distinguishing or identification coefficient, $\xi=[0,1]$ and $\Delta_{0 i}(k)$ is the deviation sequence of the reference sequence and the comparability sequence, which can be expressed in Eq.3:

$$
\begin{gathered}
\Delta_{0 i}(k)=\left\|x_{0}^{*}(k)-x_{i}^{*}(k)\right\| \\
\Delta \min =\min _{\forall} \min _{\forall k}|| x_{0}^{*}(k)-x_{j}^{*}(k) \| \\
\Delta \max =\max _{\forall j \in i} \max _{\forall k}|| x_{0}^{*}(k)-x_{j}^{*}(k) \|
\end{gathered}
$$

where $x^{*}{ }_{0}(k)$ is reference sequence and $x^{*}{ }_{j}(k)$ is comparability sequence. For the identification coefficient, the value of $\xi=0.5$ is generally used [15]. After the GRC value is calculated, the grey relational grade (GRG) is needed to derive. Normally, the average of GRC is taken to calculate the GRG which is defined in Eq.4: 


$$
\gamma_{i}=\frac{1}{n} \sum_{k=1}^{n} \xi_{i}(k)
$$

However, the Eq.4 is modified since in a real application, the effect of each factor on the system is varies. The modified grey relational grade is given in Eq.5:

$$
\gamma_{i}=\frac{1}{n} \sum_{k=1}^{n} w_{k} \cdot \xi_{i}(k) \sum_{k=1}^{n} w_{k}=1
$$

where $\mathrm{w}_{\mathrm{k}}$ refers to the normalized weights. GRG is calculated to show the relationships between the sequences. The value of GRG will be 1 if the two sequences are identity. Practically, GRG value with less than 0.6 will considered as least influential factors to the reference sequence. Table 3 shows the experimental result and also GRG value for each parameters.

Based on Table 3, it can be seen that the most minimum surface roughness is when pulse time is $100 \mu \mathrm{s}$, pulse off time is $50 \mu \mathrm{s}$, peak current is $5.7 \mathrm{~A}$, servo voltage $30 \mathrm{~A}$ and servo voltage $74 \mu \mathrm{s}$. GRA identifies the significant parameters for surface roughness in EDM process based on the GRG value. With the GRG values of 0.6502 and 0.6254 , which are the first and second highest, it can be concluded that pulse on time and servo voltage are most significant parameters to the surface roughness value in EDM process. 
Table 3. Surface Roughness value of EDM.

\begin{tabular}{|c|c|c|c|c|c|c|}
\hline Run & ON & OFF & IP & SV & $\mathbf{S}$ & $\mathbf{R a}$ \\
\hline 1 & 100 & 50 & 5.7 & 30 & 74 & 1.3974 \\
\hline 2 & 100 & 50 & 10.5 & 30 & 74 & 4.501 \\
\hline 3 & 100 & 50 & 5.7 & 90 & 74 & 4.0317 \\
\hline 4 & 100 & 50 & 10.5 & 90 & 74 & 1.886 \\
\hline 5 & 100 & 50 & 5.7 & 30 & 92 & 1.4589 \\
\hline 6 & 100 & 50 & 10.5 & 30 & 92 & 4.1478 \\
\hline 7 & 100 & 50 & 5.7 & 90 & 92 & 1.5578 \\
\hline 8 & 100 & 50 & 10.5 & 90 & 92 & 3.8676 \\
\hline 9 & 200 & 50 & 5.7 & 30 & 74 & 1.7793 \\
\hline 10 & 200 & 50 & 10.5 & 30 & 74 & 5.4328 \\
\hline 11 & 200 & 50 & 5.7 & 90 & 74 & 2.474 \\
\hline 12 & 200 & 50 & 10.5 & 90 & 74 & 2.5733 \\
\hline 13 & 200 & 50 & 5.7 & 30 & 92 & 1.9979 \\
\hline 14 & 200 & 50 & 10.5 & 30 & 92 & 2.8592 \\
\hline 15 & 200 & 50 & 5.7 & 90 & 92 & 15.1741 \\
\hline 16 & 200 & 50 & 10.5 & 90 & 92 & 2.1229 \\
\hline 17 & 100 & 70 & 5.7 & 30 & 74 & 1.8791 \\
\hline 18 & 100 & 70 & 10.5 & 30 & 74 & 2.3766 \\
\hline 19 & 100 & 70 & 5.7 & 90 & 74 & 1.5366 \\
\hline 20 & 100 & 70 & 10.5 & 90 & 74 & 4.0896 \\
\hline 21 & 100 & 70 & 5.7 & 30 & 92 & 1.6486 \\
\hline 22 & 100 & 70 & 10.5 & 30 & 92 & 5.5439 \\
\hline 23 & 100 & 70 & 5.7 & 90 & 92 & 1.7243 \\
\hline 24 & 100 & 70 & 10.5 & 90 & 92 & 2.9212 \\
\hline 25 & 200 & 70 & 5.7 & 30 & 74 & 1.6429 \\
\hline 26 & 200 & 70 & 10.5 & 30 & 74 & 2.706 \\
\hline 27 & 200 & 70 & 5.7 & 90 & 74 & 17.7071 \\
\hline 28 & 200 & 70 & 10.5 & 90 & 74 & 2.5712 \\
\hline 29 & 200 & 70 & 5.7 & 30 & 92 & 11.4499 \\
\hline 30 & 200 & 70 & 10.5 & 30 & 92 & 4.1105 \\
\hline 31 & 200 & 70 & 5.7 & 90 & 92 & 1.4481 \\
\hline 32 & 200 & 70 & 10.5 & 90 & 92 & 2.4101 \\
\hline GRG & 0.650208 & 0.619907 & 0.602967 & 0.625414 & 0.615313 & - \\
\hline
\end{tabular}




\section{Conclusion}

The machining experimental of stainless steel $316 \mathrm{~L}$ and copper impregnated graphite is conducted in die sinking EDM process in order to investigate the significant parameters of surface roughness value. Two levels full factorial experiment design is considered in this study. Based on the analysis of GRA, it was found that pulse on time and servo voltage are the most significance to the surface roughness value compared with pulse off time, peak current and servo speed.

Special appreciation to reviewer(s) for the useful advice and comments. The authors greatly acknowledge the Research Management Centre, UTM for financial support through Research University Grant (GUP) Vot. No. Q.J130000.2528.11H72

\section{References}

1 P.M. George, B.K. Raghunath, L.M. Manocha, A.M. Warrier, J. Mater. Process. Tech., 145, 66 (2004)

2 A.M. Zain, H. Haron, S. Sharif, Expert Syst. Appl., 37, 4650 (2010)

3 A.M. Zain, H. Haron, S. Sharif, Expert Syst. Appl., 37, 1755 (2010)

4 Y. Keskin, H.S. Halkaci, M. Kizil, Int. J. Adv. Manuf. Tech., 28, 1118 (2006)

$5 \quad$ N. Yusup, A.M. Zain, S. Z. M. Hashim, Expert Syst. Appl., 39, 9909 (2012)

6 M.Y. Wang, H.Y. Chang, Int J. Mach. Tools. Manuf., 44, 51 (2004)

7 A.M. Zain, H. Haron, S. Sharif, Machining Sci. Technol., 14, 43 (2010)

8 C.M. Ramirez, P. Franco, Procedia Eng, 132, 679 (2015)

9 G.K. Bose, K.K. Mahapatra, Adv. Prod. Eng. Management, 9,168 (2014)

10 M.J. Mir, K. Sheikh, B. Singh, N. Malhotra, Int. J. Eng. Sci. Technol., 4(3), 45 (2012)

11 L. Tang, Y.T. Du, Int. J. Adv. Manuf. Technol., 70, 469 (2014).

12 E. Ekici, A.R. Motorcu, A. Kus, J. Comp. Mater., 1 (2015)

13 A. Ikram, N.A. Mufti, M.Q. Saleem, A.R. Khan, J. Mech. Sci. Technol., 27 (7), 2133 (2013)

14 A.M. Deris, A.M. Zain, R. Sallehuddin, Meccanica, 48, 1937 (2013)

15 R. Sallehuddin, S.M. Shamsuddin, S.Z.M. Hashim, Int. Conf. Comp. Model. Simul., 80 (2010) 